\title{
Comparison effect of Lavender and Citrus aurantium aroma on anxiety in female students at Golestan University of Medical Sciences
}

Fozieh Bakhsha $^{1 *}$, Zahra Yousefi ${ }^{1}$, Mohammad Aryaee ${ }^{2}$, Seyyed Yaquob Jafari ${ }^{1}$, Firoozeh Derakhshanpoor $^{3}$

1. Laboratory Sciences Research Center, Golestan University of Medical Sciences, Gorgan, Iran

2. Deputy for Research, Golestan University of Medical Sciences

3. Department of Psychiatry, Golestan Psychiatry Research Center, Golestan University of Medical Sciences, Gorgan, Iran

*Corresponding author: Tel: +98 9111775765 Fax: +98 17321655

Address: Laboratory Sciences Research Center, Golestan University of Medical Science, Herkan blv begining of Road Shastkola, Gorgan, Iran

E-mail: bakhsha_fo@yahoo.com

Received; 2015/03/6 revised; 2015/11/1 accepted; 2016/03/14

\section{Abstract}

Introduction: Test anxiety is a common phenomenon and the problematic concern of the educational system. Scented essentials like lavender (angustifolia) oil and Citrus aurantium (orange flower) oil have positive impact on people's physical and mental condition and anxiety. This study was designed to compare and evaluate the effects of lavender essential oil aroma and Citrus aurantium essential oil aroma on test anxiety.

Materials and methods: This double-blind clinical trial study was carried out on 80 female students from the Faculty of Paramedics Sciences, Gorgan city in 2013. Students were randomly and equally assigned to the two lavender or Citrus aurantium groups. All students smelled oil for a period of 60 seconds. To stay scents, some oil was rubbed on the candidates foreheads using an applicator. To evaluate the level of anxiety and stress before the intervention, Sarason Anxiety Test, and to measure the effect of essence after intervention, Visual Analogue Scale (VAS) questionnaire were used. Data were analyzed using SPSS16 software and the independent and paired T-tests.

Results: The mean anxiety in students in lavender group dropped from $(5.67 \pm 2.05)$ to $(3.9 \pm$ $1.82)$ and in Citrus aurantium group decreased from $(5.25 \pm 2.06)$ to $(3.97 \pm 2)$. This difference was statistically significant $(\mathrm{P}<0.001)$. The intervention had a significant effect on heart rate; however, had no effect on the blood pressure.

Conclusion: According to the results, lavender and citrus aurantium scents had positive effects on students' test anxiety and can be used as a cheap and good psychological care in treatment support systems to control and reduce anxiety with least side effects.

Keywords: Lavender, Anxiety, Citrus aurantium

\section{Introduction}

Test anxiety, a common important educational phenomenon, is a form of situational anxiety that can lead to a significant reduction in the ability of individuals when participating in a evaluation or test session (1). Test anxiety can impact a person's cognitive processes and also can substantially interfere with their effective performance (2). Those with high test anxiety perform more weakly than others in academic achievements (3). In recent years, various methods have been used to treat anxiety, including the use of aromatherapy, fragrances which have special effects on mood, body and soul state. 
When fragrances are inhaled, they go through the olfactory ciliary limbic system (a part of the brain which controls mood, spirit and strength of learning), and reduce anxiety and fatigue, energize the body, improve focus and, in brief, build sedation pick. Thus, it can provoke thoughts and feelings by influencing inhalation or blood that consequently effect on the memory (4$7)$.

Aroma of fragrances are used for behavioral objectives and extensive range of conditions such as stress, anxiety, depression, alzheimer's disease, epilepsy, and also have an important influence on the level of attention, cognitive function, creativity, success in math, writing skills, motor skills and increase perception and memory, prevention of errors, improvement of productivity, psychology, and education, treatment of emotional problems of children with learning difficulties and support learning of foreign languages, increase the level of interest and attentiveness (8-12).

Due to the presence of substances such as terpenens, monoterpenes, and linalool, aroma of fragrances like lavender possess antibacterial, analgesic and sedative properties. Essentials obtained from Citrus aurantium contain compounds such as hydrocarbons, alcohols, and a variety of acetates, acids and phenols.

In traditional medicine, methyl anthranilate phenol, phenols of different parts of orange flower plant are used for skin freshness and vitality of the spirit, and for treating various ailments such as headaches, insomnia, relieving heart palpitations and, in final, as a tonic and diuretic $(13,14)$.

In a clinical trial study, the anxiety level of test was assessed in the two groups of nursing students by the inhalation of lavender. The results showed that anxiety levels significantly decreased in the study group (15). In a study conducted by Sakamoto et al, lavender essence increased the focus and performance in the intervention group compared to the control group (16). Also rose fragrance had antianxiety effect similar to the anti-anxiety drugs (17). Ceccarelli et al. demonstrated that the lemon aroma keeps down the corticosteroid levels in the control rats, as well (18).

Therefore, this study was designed to evaluate the effect of lavender and Citrus aurantium essence on test anxiety in female students at School of Paramedics in Gorgan city in 2013.

\section{Materials and Methods}

A double blind clinical trial carried out after approving by the Ethics Committee of the Gorgan University of Medical Sciences and registering on the Clinical Trials Site of the Health Ministry. The samples consisted of eligible female students willing to participate in the research. The participants were screened via 37-item Sarason Anxiety Test Questionnaire. Anxiety levels were categorized (mild anxiety scored 12 or less, moderate anxiety scored 13 to 20 , and severe anxiety scored greater than 20) (1921).

In this study, students who had high levels of anxiety score of 12 were participated.

Inclusion criteria were as follow: 1) oral and written informed consent to participate in the study 2) having sufficient strength of odor olfactory, 3) not suffering from anosmia, 4) lack of sensitivity to perfumes, 5) other allergies and 6) not suffering from any chronic respiratory diseases (heart conditions, blood pressure, etc). Exclusion criterion was sensitivity to essences. In this study, students were randomly divided into two groups with sample size of 80 (40 in the intervention and 40 in the control group).

The instrument was a VAS scale questionnaire. In this study, subjects were asked to score their feelings intensity ranged 0-10 that zero represents no anxiety and 10 indicates the extreme anxiety. Score of 1-3 indicates mild anxiety, 4-7 
moderate anxiety and 8-10 reports severe anxiety.

Intervention: In the night before the exam, students were exposed to breathe each essence for 60 seconds and to sustain the scent, a little oil was rubbed to the forehead of students using an applicator. The same questionnaire was used to measure the level of anxiety after 30 minutes.In this study, hemodynamic variables such as heart rate and blood pressure were measured before and after using the oil.

Ethical considerations: This study was confirmed by the Ethics Committee of Golestan University of Medical Sciences no 32189210228 dated on December 2013. All participants were also signed a written informed consent before participation and were assured of the confidentiality of their personal information. They all also had the right to withdraw from the study at any time.

\section{Statistical analysis}

Data were analyzed using independent and paired statistical t-tests and by conducting SPSS16 software. Normal distribution of data was evaluated using Kolmogorov Smirnov test. $\mathrm{P}$ value $<0.05$ was considered significant.

\section{Results}

The mean age of students was $18.3 \pm 0.25$ in lavender and 18.7 \pm 0.4 in Citrus aurantium group that had normal distribution before analysis based on t-test. The normality assumption was measured using Kolomogorov Smirnov and showed that distribution of data was normal. Table 1 describes the demographic characteristics of students. The findings of the results showed no significant difference between the cognitive profiles of the population.

Table 1. Demographic characteristics of students.

\begin{tabular}{lccc}
\hline Variables & Category & Lavender & Citrus aurantium \\
\hline Ethnicity & Fars & $30(75)$ & $31(77.5)$ \\
& Turkman & $7(17.5)$ & $8(20)$ \\
& Other & $3(7.5)$ & $1(2.5)$ \\
\hline
\end{tabular}

Data are shown as number or percent.

Findings reported that the mean of anxiety in the lavender group was $13.2 \pm 3.4$ and in the citrus group was $12.5 \pm 3.4$ measured by Sarason questionnaires, this difference was not statistically significant $(\mathrm{P}<0.431)$.

Data analysis revealed that students' anxiety in citrus aurantium groups was $5.25 \pm 2.06$ and $3.97 \pm 2$ before and after intervention, respectively using VAS scale. Anxiety mean the in lavender group was $5.67 \pm 2.05$ before and $3.9 \pm 1.82$ after intervention that was not statistically significant $(\mathrm{P}<0.359)$. The mean of citrus aurantium anxiety in the intervention group was $3.97 \pm 2.0$, and anxiety after the intervention in the lavender group was 3.9 \pm 1.28 , this difference was not statistically significant $(\mathrm{P}<0.862)$.

The mean anxiety level of students was significantly decreased in the lavender and citrus aurantium after the intervention compared to before the intervention and, this difference was significant, as well $(\mathrm{P}<$ $0.001)$. The results showed a significant difference in pulse rate of students in both lavender and citrus aurantium groups after the intervention than before the intervention (Table 2).

Table 2. Average heart rate before and after intervention in Lavender.

\begin{tabular}{lccc}
\hline Pulse & Before intervention & Citrus aurantium group & After intervention \\
\hline Lavender Group & $77.3 \pm 8.8$ & $73.95 \pm 8.9$ & $\mathrm{P}<0.019$ \\
Citrus aurantium Group & $76.3 \pm 9.0$ & $72.55 \pm 9.3$ & $\mathrm{P}<0.001$ \\
\hline
\end{tabular}

Data are shown as mean \pm SD. 
The current results showed that difference in the mean of systolic blood pressure of students in the lavender group was not statistically significant $(P<0.245)$. In addition, the mean of systolic blood pressure in the citrus aurantium group was not also statistically significant $(\mathrm{P}<0.35)$, however, the mean of diastolic blood pressure in the citrus aurantium group was statistically significant $(\mathrm{P}<0.002)$ (Table 3).

Table 3. Mean Systolic Blood Pressure before and after the Intervention in Lavender Group

\begin{tabular}{lccc}
\hline Systolic blood pressure & Before intervention & Citrus aurantium group & After intervention \\
\hline Lavender Group & $106.05 \pm 17.56$ & $101.43 \pm 16.59$ & $\mathrm{P}<0.25$ \\
Citrus aurantium Group & $105.3 \pm 17.8$ & $102.13 \pm 9.6$ & $\mathrm{P}<0.35$ \\
\hline
\end{tabular}

Data are shown as mean \pm SD.

\section{Discussion}

In this study, test anxiety levels of female students measured by Sarason questionnaires were $\% 14.4$ mild, \% 75.4 moderate and \% 10.2 severe anxiety. In a study conducted by Ghazanfari and Moaddeli, 90 percent of students had low test anxiety (22). The Heravi et al. study revealed that $\% 5.62$ of the subjects in the treatment group and \% 5.53 in the control group had an average pre-intervention test anxiety (23). In the Clark et al. study, most of the subjects had high test anxiety (24). Differences between the studies on test anxiety might be affected by various factors and students perception of these items.

Moaddeli and Ghazanfari believed that factors such as the difficulty of the course, the exam questions designed by teachers and the educational system may effect on the anxiety level of students (22). Obviously, these factors are not identical in different colleges, so a major part of the differences in the several studies can be attributed to these factors.

Lavender and Citrus aurantium are usually used for chronic pain, depression, anxiety, some cognitive disorders, insomnia and stress-related illness, sedative and anxiolytic properties $(4,25)$.

Aydin et al. in a study to determine the effect of aromatherapy in learning a foreign language examined the effect of lemon, rose and lavender in 58 elementary school students, results showed that the knowledge and learning levels of students in the study group was almost twice greater than those in the control group. Moreover, cognitive achievement of those who had inhaled rose and lavender aromas was significantly higher. It was also noted that the study group had lower dementia than the control group (8). This present study also showed that mean anxiety of students in the citrus aurantium and lavender was $5.25 \pm 2.06$ and $5.67 \pm 2.05$ before and after the intervention, respectively that decreased to $3.97 \pm 2.0$ and $3.9 \pm 1.82$ after the intervention, which represents a significant reduction of anxiety in people who inhaled citrus aurantium and lavender compare to before intervention.

The results of the study are consistent with those examined by Yilmaz, Fowler, Morris and other studies that have used essential oils in stress situations such as Itai, Berns, Zare, Seraj and Vakilian, Lehrner, and Kanaani. It may be caused by exposure of the sample for more than 30 minutes $(6$, $15,26-30)$. However, this study is not in line with the study of Mozzarlli and Graham. In Mozzarrelli study, a statistically significant difference was observed in anxiety levels after inhalation of lavender and placebo $(31,32)$.

In response to stress, the limbic system can secrete enkephalins, endorphins and serotonin. When this system is affected by lavender exerts, its psychological effects create a sense of tranquility $(32,33)$. 
RE et al. in their study concluded that the linalool presented in lavender inhibits the release of acetylcholine and changes the ion channel function in the neuromuscular junction.

Lynalyl acetate functions as a narcotic and sedative agent (34). Wilson and Walsh showed that consumption of lavender and other plants improves the mood of patients and decreases psychological problems (35).

To examine the effects of citrus aurantium on anxiety of animal models, Pultrini noted the combination of Mycrene and Limonen of citrus aurantium and reported the biological properties of these two compounds with inhibitory effects on the central nervous system that finally reduces anxiety (36).

Carvalho et al. delineated the anxiolytic and sedative effects of citrus aurantium as an anxiolytic compound (14).

Lehner was also showed that broadcasting the citrus aurantium in dental waiting room reduced the anxiety of patients (28). These studies are consistent with the results of the present study.

Since anxiety is an unpleasant state, vague and associated with the irritation of autonomic nervous system, headache, sweating, heart palpitations, muscle cramps, chest, stomach discomfort and restlessness (37), in current study, pulse rate and hypertension of students in both lavender and citrus aurantium were measured and after the intervention, students showed a great sense of relief.

In Khoori's research on the effect of citrus aurantium on the electrophysiological properties of rabbit atrioventricular node showed that flavonoids can reduce heart Miran (38).

Park and Lee study of inhalation aromatherapy on nursing students showed low levels of physical symptoms of anxiety and stress in the intervention group (9). In Mijong Kim study on heart rate it also had an effect (39). Seo JY in a study to evaluate the effect of aromatherapy on stress and tension response in 36 teenage girls concluded that students' stress levels were significantly lower when received scent as compared to the receiving placebo (40).

These studies are consistent with our study, and also in relevance with the study conducted by Shabanian et al. found no significant changes in heart rate (41). Thus it can be concluded that inhaling scent can be a very effective technique for stress management for test anxiety.

In the present study, lavender and noreli effects had no significant effect on systolic blood pressure.

Hwang $\mathrm{JH}$, in a study implemented to determine the effects of aromatherapy on stress and blood pressure in patients with primary hypertension, divided fifty-two patients into an essential group and a placebo group.

He blended lavender, ylang-ylang and bergamot oils and by using of inhalation method once daily, measured and recorded blood pressure for 4 weeks, pulse, serum cortisol and catecholamine levels twice weekly, objective stress and test anxiety before and after treatment in the three groups. He concluded that blood pressure, pulse, mental stress, anxiety and serum cortisol levels in the three groups were statistically significantly different (42). Perhaps the cause of this difference is the presence of pharmaceutical compounds or the age range of patients under study in which situation the blood pressure changes are minimal for this age period.

\section{Conclusion}

High test anxiety of an individual can change their mood state and cause fatigue and depression, and diminish or disrupt their mental and cognitive abilities (e.g. attention, concentration and memory).

With regard to results of this study, it can be concluded that lavender and noreli aromas can control and reduce the anxiety of the students, and improve their mood and spirit.

To avoid the negative effects of pharmacological and chemical agents and 
to control these situations, perfumes and natural oils can be used that having pleasant natural fragrances with least side effects and low costs.

It is suggested that lavender and noreli aroma effects also evaluate with further samples in exam environments.

\section{References}

1. Sarason IG. Test anxiety: Theory, research, and applications: Lawrence Erlbaum Assoc Inc; 1980.

2. Bertrams A, Englert C, Dickhäuser O, Baumeister RF. Role of self-control strength in the relation between anxiety and cognitive performance. Emotion. 2013;13(4):668.

3. Cassady JC, Johnson RE. Cognitive test anxiety and academic performance. Contemp Educ Psychol. 2002;27(2):270-95.

4. Cooke B, Ernst E. Aromatherapy: a systematic review. Br J Gen Pract. 2000;50(455):493-6.

5. Buckle J. Aromatherapy inperianesthesia nursing. J Perianesth Nurs. 1999;14(6):336-44.

6. Morris N, Birtwistle S, Toms $M$. Anxiety reduction by aromatherapy: anxiolytic effects of inhalation of geranium and rosemary. Int $\mathbf{J}$ Aromather. 1995;7(2):33-9.

7. Delgado AC. What is aromatherapy?. Revista de enfermeria (Barcelona, Spain). 2005;28(5):55-8, 61-4.

8. Aydin S. The Effect of Computers on the Test and Inter-Rater Reliability of Writing Tests of ESL Learners. Online Submission. 2006;5(1).

9. Park MK, Lee ES. The effect of aroma inhalation method on stress responses of nursing students. Taehan Kanho Hakhoe Chi. 2004;34(2):344-51.

10. de Almeida RN, Motta SC, de Brito Faturi C, Catallani B, Leite JR. Anxiolytic-like effects of rose oil inhalation on the elevated plus-maze test in rats. Pharmacol Biochem Behav. 2004;77(2):361-4.

\section{Acknowledgement}

The authors gratefully thank the Deputy of Research at Golestan University of Medical Sciences and Center for Psychiatric Research for their approval of proposal for this clinical trial research project.

11. Da Porto C, Decorti D. Analysis of the Volatile Compounds of Flowers and Essential Oils from EM EMTYPE. Planta Med. 2008;74(02):182-7.

12. Washburn D, Jones L, Satya R, Bowers C, Cortes A. Olfactory use in virtual environment training. Modeling \& Simulation. 2003;2(3):19-25.

13. Wagner H, Hikino H, Farnsworth NR. Economic and medicinal plant research: Academic Press; 2012.

14. Carvalho-Freitas MIR, Costa M. Anxiolytic and sedative effects of extracts and essential oil from Citrus aurantium L. Biol Pharm Bull. 2002;25(12):1629-33.

15. Kutlu AK, Yılmaz E, Çeçen D. Effects of aroma inhalation on examination anxiety. Teaching and Learning in Nursing. 2008;3(4):125-30.

16. Sakamoto R, Minoura K, Usui A, Ishizuka Y, Kanba S. Effectiveness of aroma on work efficiency: lavender aroma during recesses prevents deterioration of work performance. Chem Senses. 2005;30(8):683-91.

17. de Almeida RN, Motta SC, de Brito Faturi C, Catallani B, Leite JR. Anxiolytic-like effects of rose oil inhalation on the elevated plus-maze test in rats. Pharmacol Biochem Behav. 2004;77(2):361-4.

18. Ceccarelli I, Lariviere WR, Fiorenzani P, Sacerdote P, Aloisi AM. Effects of long-term exposure of lemon essential oil odor on behavioral, hormonal and neuronal parameters in male and female rats. Brain Res. 2004;1001(1):78-86. 
19. Sapp M. Test anxiety: Applied research, assessment, and treatment interventions: University Press of America; 2013.

20. Spielberger CD. Test anxiety inventory: Wiley Online Library; 1980.

21. Braden R, Reichow S, Halm MA. The use of the essential oil lavandin to reduce preoperative anxiety in surgical patients. J Perianesth Nurs. 2009;24(6):348-55.

22. Moadeli Z, Ghazanfari Hesamabadi M. a survy on the studets'exam anxity in the fatemeh(PBUH) college of nursing and midwifery, spring 2004. Strides in Development of Medical Education. 2004.

23. Heravi M, Jadid Milani M, Regea N, Valaei N. [The effect of relaxation training on exam driven anxiety level among nursing students]. J Univ Mazandaran Med Sci. 2004;14(2):218. (Persian)

24. Clark J, Fox P, Schneider H. Feedback, test anxiety and performance in a college course. Psychol Rep. 1998;82(1):203-8.

25. Barocelli E, Calcina F, Chiavarini M, Impicciatore M, Bruni R, Bianchi A, et al. Antinociceptive and gastroprotective effects of inhaled and orally administered Lavandula hybrida Reverchon "Grosso" essential oil. Life Sci. 2004;76(2):213-23.

26. Fowler NA. Aromatherapy, used as an integrative tool for crisis management by adolescents in a residential treatment center. J Child Adolesc Psychiatr Nurs. 2006;19(2):69-76.

27. Seraji A, Vakilian K. The comparison between the effects of aromatherapy with lavender and reathing techniques on the reduction of labor pain. complementary Med J. 2011;1(1):3441.

28. Lehrner J, Marwinski G, Lehr S, Johren P, Deecke L. Ambient odors of orange and lavender reduce anxiety and improve mood in a dental office. Physiol Behav. 2005;86(1):92-5.
29. Itai T, Amayasu H, Kuribayashi M, Kawamura N, Okada M, Momose A, et al. Psychological effects of aromatherapy on chronic hemodialysis patients. Psychiatry Clin Neurosci. 2000;54(4):393-7.

30. Burns EE, Blamey C, Ersser SJ, Barnetson L, Lloyd AJ. An investigation into the use of aromatherapy in intrapartum midwifery practice. J Altern Complement Med. 2000;6(2):141-7.

31. Muzzarelli L, Force M, Sebold M. Aromatherapy and reducing preprocedural anxiety: A controlled prospective study. Gastroenterol Nurs. 2006;29(6):466-71.

32. Graham P, Browne L, Cox H, Graham J. Inhalation aromatherapy during radiotherapy: results of a placebocontrolled double-blind randomized trial. J Clin Oncol. 2003;21(12):23726.

33. Akhondzadeh S, Kashani L, Fotouhi A, Jarvandi S, Mobaseri M, Moin M, et al. Comparison of Lavandula angustifolia Mill. tincture and imipramine in the treatment of mild to moderate depression: a double-blind, randomized trial. Prog Neuropsychopharmacol Biol Psychiatr. 2003;27(1):123-7.

34. Re L, Barocci S, Sonnino S, Mencarelli A, Vivani C, Paolucci G, et al. Linalool modifies the nicotinic receptor-ion channel kinetics at the mouse neuromuscular junction. Pharmacol Res. 2000;42(2):177-82.

35. Walsh E, Wilson C. Complementary therapies in long-stay neurology inpatient settings. RCNP. 1998;13(32):32-5.

36. de Moraes Pultrini A, Almeida Galindo L, Costa M. Effects of the essential oil from Citrus aurantium L. in experimental anxiety models in mice. Life Sci. 2006;78(15):1720-5.

37. Sadock BJ, Kaplan HI, Sadock VA. Kaplan \& Sadock's synopsis of psychiatry: behavioral sciences/clinical 
psychiatry: Lippincott Williams \& Wilkins; 2007.

38. Rakhshan E, MirAbbasi A. [The effect of essence of Citrus aurantium on the electrophysiological properties of isolated perfused rabbit $\mathrm{AV}$-node]. $\mathrm{J}$ Gorgan Univ Med Sci. 2006;8(2):17.(Persian)

39. Kim M, Hwangbo HH. Randomized trial evaluating the aroma inhalation on physiological and subjective anxiety indicators of the nursing students experiencing the first intravenous injection. IJBSBT. 2010;2(4):1-9.
40. Seo J-Y. The effects of aromatherapy on stress and stress responses in adolescents. J Korean Acad Nurs. 2009;39(3):357-65.

41. Shabanian GR, Pouria Mofrad E, Akhlaghi M. [Comparison of the effect of citrus aurantium diazeepam and on preoprativve anxiety]. Sharekord Uni Med Sci J. 2009.(Persian)

42. Hwang JH. The effects of the inhalation method using essential oils on blood pressure and stress responses of clients with essential hypertension. Taehan Kanho Hakhoe Chi. 2006;36(7):1123-34. 